\title{
Co Production of Critical Energy Materials
}

\author{
Phil Keller and Corby Anderson* \\ Kroll Institute for Extractive Metallurgy, USA
}

*Corresponding author: Corby Anderson, Golden, Colorado 80401, USA

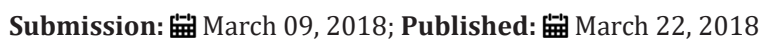

\section{Introduction}

This issue of material criticality has been receiving much attention recently from governments all over the world. The United States and the European Union have two different definitions of what makes a material critical. The United States Department of Energy (DOE) defines criticality in two ways:

a. Supply based risk based on projected market balances, competing energy demands, political, regulatory and social factors, co-production risks, and producer diversity

b. Importance to clean energy based on clean energy demand and substitutability [1]. Net import reliance can hint at the supply based risk for materials.

Figure 1 shows the United States net import reliance in 2016 for some Critical Energy Materials of interest [2].

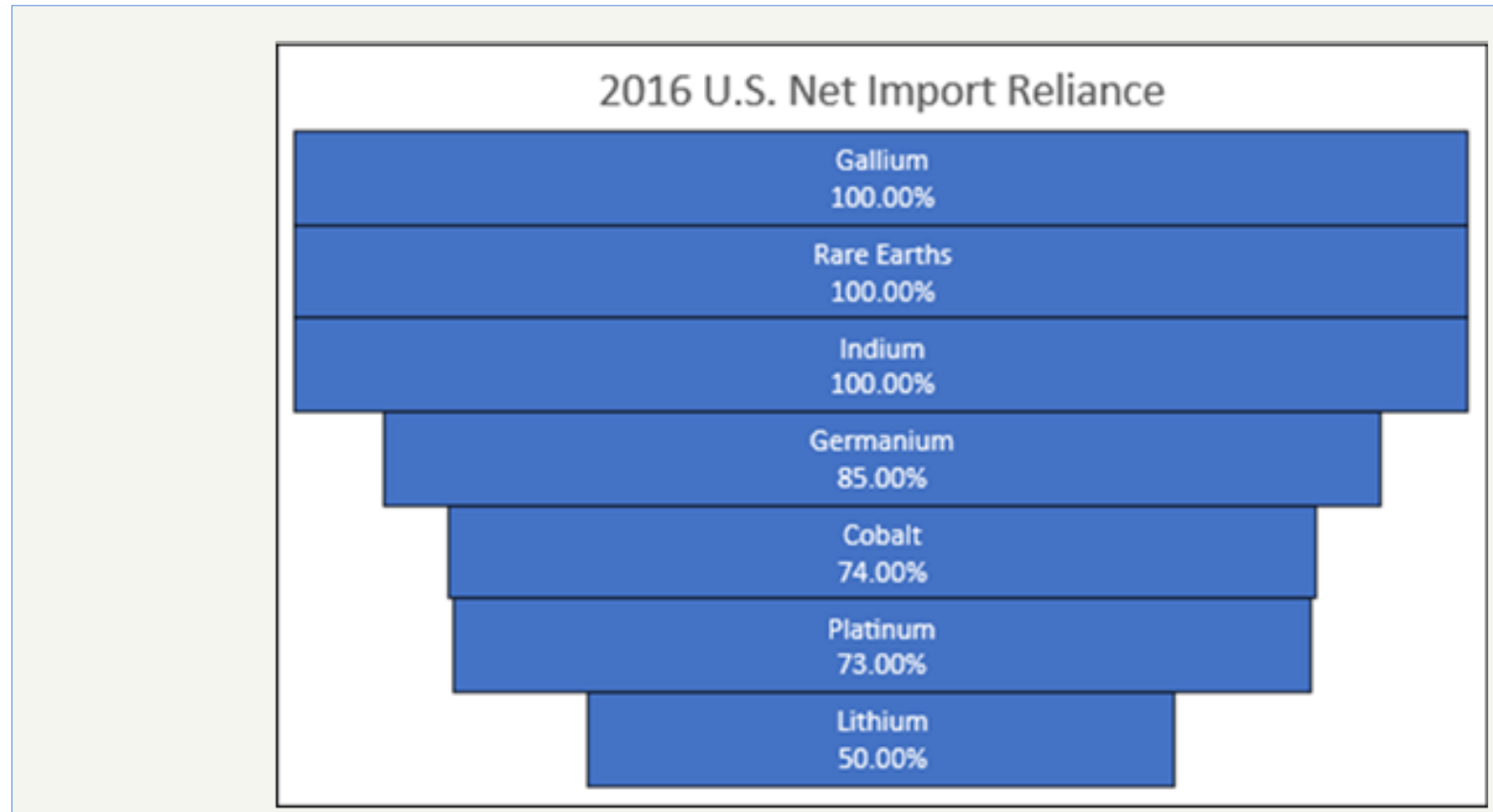

Figure 1: United States net import reliance for some critical energy materials [2].

The European Union defines a material as critical when "the risks of supply shortage and their impacts on the economy are higher than for most of the other raw materials" [3]. From these two definitions, it is clear that the European Union takes a more broad approach to defining critical materials than the US DOE does. Essentially both government organizations define a material as critical when it provides essential properties to a modern engineered material and is subject to supply risk. The purpose of this paper is to summarize current efforts to increase supply stability of critical materials through byproduct or co product production alongside more common elements. A subsequent publication will detail the production of byproduct production for cobalt, rare earth elements, lithium, gallium, germanium, indium, manganese, tellurium, graphite and the platinum group metals.

Accordingly, a metal can be defined as a byproduct if the revenue gained from the sale of that metal is not enough to cover the full cost of the mine. On the other hand, if the full costs of the mine can be covered solely by the sale of the minor metal, then it is considered a co product [4]. Minor metals, such as the critical materials listed above, are not economically viable to mine as a primary material and are therefore mined as a byproduct to materials that are able to produce enough revenue to cover mine 
expenses. This allows increased quantities of critical materials to be recovered and can help to relieve supply risks and shortages. Figure 2 shows a chart which describes metal companionability.
This Figure shows which metals are usually associated with more commonly mined elements.

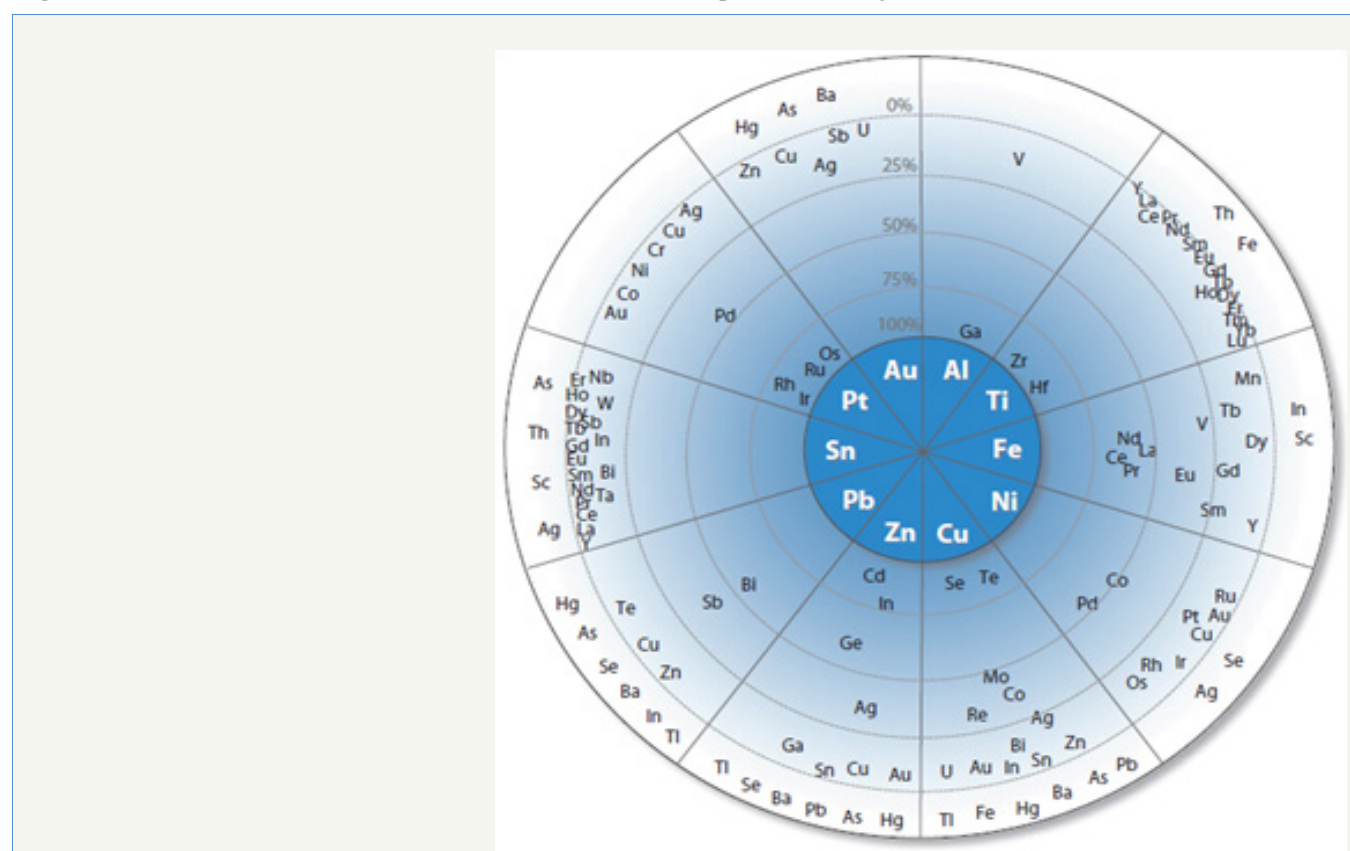

Figure 2: Principal host elements are in the center of the diagram. Surrounding the host metals are elements that are spaced proportionally to the percentage of their primary production that originiates with the indicated host element [4].

\section{Conclusion}

Critical materials are so labeled because they are of large importance to modern engineered objects but are subject to supply risks. As outlined in this paper, many options for byproduct production of critical materials exist. While all critical materials have a potential byproduct source, more research must be completed to optimize these procedures. Byproduct production of these materials will be able to help alleviate supply shortages.

\section{References}

1. Eggert RG, IMPC 2016: XXVIII international mineral processing congress proceedings. Canadian Institute of Mining, Metallurgy and Petroleum IMPC, ISBN : 978-1-926872-29-2, pp. 1-10.

2. US Geological Survey (2017) Mineral commodity summaries 1: 1-194.

3. Espinoza LT, Gandenberger C (2011) Critical raw materials and the EU, pp. 737-745.

4. Nassar NT, Graedel TE, Harper EM (2015) By-product metals are technologically essential but have problematic supply 1(3): 1-11.
Creative Commons Attribution 4.0 International License

For possible submissions Click Here

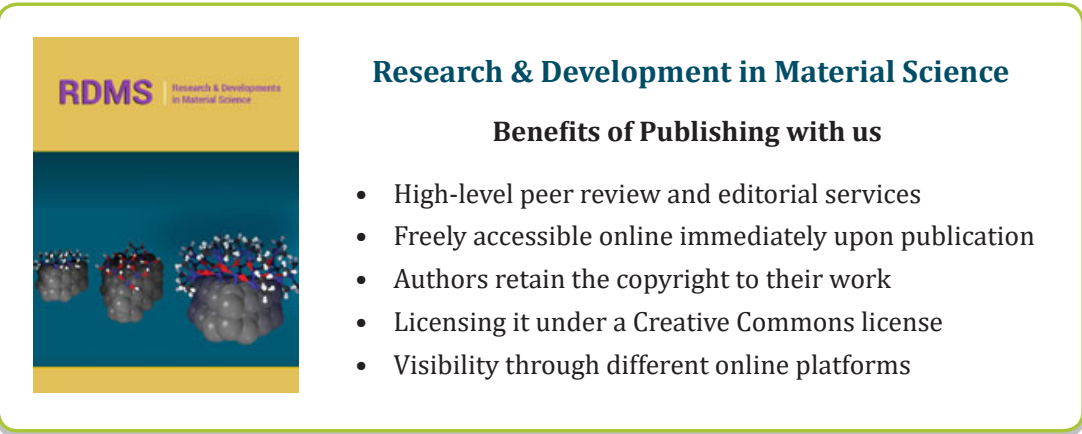

